\title{
Culture of innovation sustainable development of industrial parks Evaluation System
}

\author{
Liu Shuyan, Wang Yumei \\ Qingdao University of Science and Technology College of Economics and Management \\ Qingdao 266061 \\ Email:sixu1016@163.com
}

\begin{abstract}
Capacity for sustainable development of the creative and cultural industrial park evaluation index system is decomposed into two modules on the basis of the status quo and development potential. The basis of the status quo of the creative and cultural development of industrial parks can be further divided for the endogenous competitive and external environment. The endogenous competitiveness is the source for the development of the park, the external environment for its development policy, services support and complement each other both inside and outside, are indispensable. From both angles were set to the two-level indicators of the competitiveness of endogenous and external environment.
\end{abstract}

Keywords- Cultural and creative industries; park; sustainable development; evaluation $s$

\section{INTRODUCTION}

Creative cultural industry has its own characteristics, that is, the industry usually consists of a large number of smallscale enterprises in the market, each enterprise usually has a certain market forces, which hold a certain number of specific consumer groups, while in the production, product which core is running creativity depends on the degree of integration of knowledge, technology and culture, management depends on the degree of spiritual joy of the creative staff, circulation degree of humanity depends on the demand for products and the maintenance of the property rights system. Therefore, based on the creative production, management and distribution characteristics of cluster organization, use of appropriate cluster structure will be able to greatly improve the overall competitiveness of the industry, help creative enterprises optimize knowledge sharing mechanism, expand the ecological space, grasp the market trends and achieve the historical mission of the industry in the development of the economy as a whole. This requires research cluster organizational issues of cultural and creative industries park.

\section{THE DESIGN FRAMEWORK AND MEASURE VARIABLES OF CREATIVE CULTURAL INDUSTRY PARK SUSTAINABLE DEVELOPMENT EVALUATION INDEX SYSTEM}

A. creative culture Industrial Park subsystem specifications for sustainable development in the evaluation of the competitiveness of endogenous.Four secondary indicators, cultural resources, creative ability, degree of industrialization and concentration degree, respectively, the

\section{following analysis:}

(1)Cultural resources (A)

Set the starting point of the index system of cultural resources is necessary to reflect the content of the cultural elements of the creative and cultural industries, but also need to make a description of the development of the creative and cultural capital in the creative and cultural industrial park. Its sub-indicators, to measure the number of existing historical and cultural resources; same time, the cultural resources due to the creative and cultural industries and activities and of the economic, cultural, and social life highly correlated, it reflected in the social and cultural resources; influence can well reflect the development potential of the development of the cultural resources and cultural capital, the index system set the historical and cultural resources (A1), the social cultural resources (A2) and cultural resources influence (A3) to examine the cultural resources.

Historical and cultural resources (A1) is left over from history, and is already taking shape cultural resources, in accordance with the existing forms of cultural resources can be divided into the material and cultural resources and nonmaterial cultural resources, and cultural resources of the total embodied not only by the number, but also should reflect the value and contribution, this point can be embodied by its visibility, reflecting the development status of cultural resources is not only the development amount, more important, its follow-up to the degree of protection. Summing up the above analysis, the key measure variables that reflect the historical and cultural resources: substance at or above the provincial level, the non-material cultural heritage number (A11), above the provincial level artist, intangible cultural heritage inheritors number (A12), the annual cultural resource protection funds put into (A13).

At this stage, the historical and cultural resources of the park's cultural capital have equally important with the formation and development of the cultural capital. To do this, set the social and cultural resource indicators (A2) at this stage of the formation and development of the cultural capital utilization to reflect the concerns and input from universities, research institutions, the perspective of the unit in charge of the park on the social and cultural capital. The key variables: the measure of social and cultural resources by relying on a number of universities, research institutions (A21) are relying on the kind of unit in charge of funding the total (A22), relying on the unit in charge of management investment accounted for park management team specific gravity (A23). 
From cognitive and interests of the content of the relevant media reports, academic recognition as well as the public interest in these creative and cultural industrial park are effective indicators to measure cultural resources influence (A3). Therefore, this study reflect cultural resources influence key measure variables: domestic and international mainstream websites, newspapers, magazines reported that the number of (A31), at home and abroad to the cultural resources for academic research subject article number (A32), tourism flow(A33).

(2) Creative ability (B)

The starting point is the creative ability index set to reflect the level of creativity and creative ability of the creative and cultural industry enterprises in the park. Despite almost all industries in the contemporary economy contains certain innovative or creative, but creative and cultural industries as a creative cultural products and services for the object's unique industry, creativity is the essential requirement is also the main characteristics. By examining the creative human capital to reflect the qualities and abilities of the employees in these industries, especially the creative talents, fundamental to the development of cultural and creative industries; Creative Technology Capital by examining means of science and technology with the creative achievements to reflect the degree of integration, to reflect changes in technology $\mathrm{R} \& \mathrm{D}$ investment and creative input. The creative conversion capability determines the level of the corporate conversion ability and level of creative thinking to creative products, is the driving force and source of the sustainable development of enterprises is an important indicator to evaluate the potential for the development of SMEs. Therefore, the index system is set creative human capital (B1), Creative Technology Capital (B2), the creative conversion capability (B3) three indicators to examine creative ability.

Reflect the Creative human capital (B1) key measure variables: the number of practitioners of cultural and creative industries accounted for the number of employees of the city's cultural and creative industries the proportion of (B11), the number of practitioners undergraduate education in the creative and cultural industries (B12), the cultural and creative industries practitioners Intermediate more than the number of technical titles (B13), the average income of the average income and the city in the same industry in creative and cultural industry practitioners than (B14).

The key measure variables reflecting Creative Technology Capital (B2): R \& D investment in total (B21), invention patent, copyright Quantity (B22), the number of computers (B23).

The measure creative conversion capability (B3) key variables: per thousand of the invention patent the copyright number (B31), new technology, new product sales proportion of total revenue (B32), the past three years, patents for inventions, writings authorized new increase in average number of (B33), creative achievements conversion platform number (B34).

(3) The degree of industrialization (C)

Industrialization is the ultimate expression of creative culture as an industry, and the establishment of the indicators of the degree of industrialization is the creative and cultural industries visits Park industrial scale and level. Comprehensive industrialization of the relevant literature, an industry's level of industrialization can reflect from two levels of scale, efficiency, and therefore, the index system design industrial scale (C1), industrial efficiency (C2) two three indicators to examine creative degree of industrialization, cultural and industrial park.

Reflect the key measure of the scale of industrialization (C1) variables: total assets of cultural and creative industries (C11), creative and cultural industry profits gross (C12), the number of creative cultural industry enterprises accounted for the proportion of the number of the enterprises in the park (C13), creative culture the industry's output value accounts for the proportion of total output value of the park (C14), the number of practitioners of cultural and creative industries accounted for the total number of employees of the Park, the proportion of (C15).

Reflect the key measure of industrial efficiency (C2) variable: the past three years, the creative and cultural industry average growth rate of total assets (C21), the output growth of cultural and creative industries contribute to the park output value growth rate (C22).

(4)Agglomeration degree (D)

The main purpose of the creative and cultural industry park lies in the development of related industries gather to fully embody the agglomeration effect, the establishment of the indicators of the degree of concentration that is for measuring the concentration of the industry in the park as well as cultural and creative industries degree of polymerization of the units. Concentration reflects the degree of specialization of the leading industries, the degree of polymerization is the organic polymeric between the degree of development of the industry chain and related actors, the degree of collaborative innovation, the inherent characteristics of industrial clusters. Concentration degree is not only reflected in the economic as gathered and industry output value of the degree of specialization, efficiency reflected the combined effect of realization. Therefore, the establishment of a concentration in the indicators of the degree of concentration (D1), the polymerization degree (D2) and the agglomeration effect three indicators (D3).

Concentration (D1) is mainly used to measure the degree of concentration of the various elements and actors in the park. Therefore, a key measure of the degree of concentration indicators: number of creative and cultural industrial park within the creative culture leading enterprises accounted for the city creative culture number of leading enterprises in the proportion of (D11), the location entropy coefficient (D12), industry index (target model) (D13) . The location entropy index [i] The share of industry in the region and the economy as a whole, the industry occupies a given ratio. Industry index [ii] is a measure of the degree of agglomeration of industrial space indicators.

The degree of polymerization (D2) angle from the different economies in the creative and cultural industry park in the concentration factors of production, economic output, and the maturity of the industry chain, to reflect the degree of economic ties between the creative and cultural enterprises in 
the region, in order to assess the economic competitiveness of the creative and cultural industrial park geospatial gathering. Reflect the degree of polymerization of the key measure variables: the enterprises to participate in the creative and cultural industry park public exchanges the annual average number of times (D21), intermediary services, the number of institutions (D22), all enterprises in the cultural and creative industries park trade revenues accounted for the proportion of total income the mean (D23), Mean enterprises to participate in the cultural and creative industries park Union Association (D24).

Enterprises engaging in the creative and cultural industries together, companies use public facilities commonly, reduce the scattered layout required an additional basis for investment and save the cost of the transfer of material and information benefiting from the geographical advantages. Besides, the internal park companies can form the external economies of scale and reduce the average cost of each enterprise through a specialized division of labor and effective technical cooperation, it contributes to the formation of the virtuous cycle, and improves the overall economic strength of the entire creative and cultural industrial park. In addition, the enterprises of creative and cultural industry in the park must establish a common industrial culture and values, cooperation and trust-based social network, and a good reputation on the external form. Therefore, the key measure variables of reflecting the agglomeration effect include: the agglomeration scale income coefficient (D31), Average speed of new enterprises to enter the park in the past three years (D32), Average reduction of the cost of business (D33). Income coefficient of agglomeration scale is the index of reflecting the scale income level lift by the agglomeration effect [iii].

B. The external environment subsystem of Creative Cultural Industry Park Sustainable Development Evaluation

\section{(1)Hard environment (E)}

Creative and cultural industry cluster formation. Places which have more perfect hard environment, the better they can gather the creative and cultural production and consumption of the creative and cultural products. Therefore, the three indicators foundation facilities (E1) are set under the two indicators hard environment.

The key measure variables that reflect infrastructure: total gross floor area (E11), the number of public cultural infrastructure (E12), per capita infrastructure investment (E13), financial functional areas within the park area (E14), within the park and $1 \mathrm{~km}$ range through a number of subway, bus lines (E15), the park geographical location (E16).

(2)The soft environment $(F)$

The management of service levels (F1) and policy environment (F2) two three indicators are made under the two indicators soft environment.

The key measure variables that reflect the level of management services: enterprise innovation services satisfaction degree (F11), the number of public service platform (F12), public services, the number of items (F13), Public Services Enterprise coverage (F14), management services team Master or above accounted for a proportion of the total number of management services team (F15).

Key measure variables that reflect the policy environment variables: total financial assistance of regional governments (F21), the regional government tax incentives (credits) proportion (F22), enterprises, individuals on the effects of policy support recognition (F23).

Finally, we examine the capacity for sustainable development of a creative and cultural industrial park, also must measure the potential for the development of the creative and cultural industrial park.

Development potential is the motivation of sustainable development of a culture industry park. It is measured by three indicators: development potential of economy (G), financing capacity $(\mathrm{H})$ and the international level.

The value added in a certain industry and the momentum of such reflect the potential of it. Both of them are crucial for a sunrise industry that has a good prospect and enjoys abundant potential effective market demand. Room for a culture park renders it more attractive to foreign investment and partners. More room leads to more promising prospect. As a conclusion, the ratio of the value added of the industry to that of the whole city (G11), the index that measures the leading industry (G12), room for the development of the park (m2) (G13) are to calculated when evaluating the developmental potential of the economy.

Variables that reflect the financing capacity are average increment of the listed companies in the last three years (H11) and the growth rate of overseas investment in the last three years (H12).

Variables that reflect the international level are the acceleration of international joint ventures and cooperative projects in the last three years (I11) and the average growth of the foreign exchange earned through exports in the last three years (I12).

\section{CONCLUSION}

Given within twins creative cultural industry park sustainable development evaluation system and the external environment subsystem index system, the reference to the theory of quantitative analysis and evaluation of indicators of sustainable development for the creative and cultural industrial park. The endogenous competitiveness subsystem sustainable development in the creative and cultural industrial park, will be divided into four secondary index system of cultural resources, creative ability, degree of industrialization, the concentration degree. Valuation of sustainable development for the creative and cultural industrial park, can be divided into two hard environment and soft environment index system.

\section{ACKNOWLEDGMENT}

This work was financially supported by the Shanghai University Science Foundation (J11WG10;), 2012 EI010.

\section{REFERENCES}

[1] Zhu Dajian,Wang Hongbing. Build a creative city --- 21 century urban development in Shanghai core value [J]. Urban Planning, 2007,46 (3) :20-24 
[2] John Howkins. The Creative Economy : How People Make Money from Ideas[M]. London : Penguin Books,2002. 116

[3] Liu Ying, Beijing University of Beijing and creative industries cluster development research [D]. Dissertation 2008

[4] Wang Ronghua. Foster the development of creative industries to explore and practice [M]. Shanghai: Shanghai Science and Technology Literature Publishing House, 2006.219

[5] Zeng Guang, Zhang Xiaoqing creative industries cluster characteristics of its development strategy [J].,441,447-448 of the Science and Technology Management Research .2009 (6) 